\title{
The Gold-Exchange Standard
}

Rodrigo Oliveira de Lima ${ }^{1}$

\section{Resumo}

Este artigo discute o final do padrão ouro e o estabelecimento do dólar como mantenedor das paridades de câmbio. A sua proposição é a de que tanto os Estados Unidos como a França operaram no sistema financeiro internacional o fim da paridade do ouro. O desequilíbrio na balança de pagamentos dos Estados Unidos, tese correta dada a preferência do mundo pelo dólar, foi redistribuído em recursos de créditos e empréstimos internacionais, e que é apresentado empiricamente como uma preferência das principais potências por conversíveis financeiros.

Palavras-Chave: Padrão ouro. Conversibilidade. Relações internacionais.

\section{Abstract}

This article discusses the end of the gold standard and the establishment of the dollar as maintainer of exchange parities. His proposition is that both the United States and France have operated in the international financial system in order to parity gold. The imbalance in the balance of payments of the United States, thesis correct given preference in the world by dollar was redistributed resources from international loans and credits, and that appears empirically as a preference by major powers convertible financial.

Keywords: Gold standard. Convertibility. International relations.

\section{Introdução}

Nos círculos das Nações Unidas especulou-se sobre os possíveis efeitos da crise monetária na Europa, ainda nos anos 1960, que enfraqueceria sobremaneira a posição da França e tenderia a fortalecer a posição da Alemanha no mundo. É um fato político incontestável que, ainda presa a um complexo de culpa ligado à última Guerra Mundial, Bonn sempre apresentará uma ação diplomática que fica muito aquém da que

1 Pós-Doutorando em Relações Internacionais, Doutor em Ciências Sociais, também em Relações Internacionais, pela Pontifícia Universidade Católica de São Paulo (2011). Mestre em História Social pela Pontifícia Universidade Católica de São Paulo (2006). Possui graduação e Licenciatura em História pela Pontifícia Universidade Católica de São Paulo (2002). Tem experiência na área de Ciência Política, Política Externa e Relações Internacionais. Atuante nos seguintes temas: História, Política Externa e Relações Internacionais. Pesquisador bolsista CNPq de Iniciação Científica, Mestrado e Doutorado. Membro do Núcleo de Análise e Conjuntura Internacional, NACl, PUC-SP. Relações Internacionais. 
corresponderia à sua importância econômica e industrial. As novas crises financeiras, que significam o preço a ser pago pela Europa por suas desordens neste campo poderão levar os alemães a uma posição menos resignada e mais afirmativa. Pois é essa uma circunstância refletida no antigo complexo das relações Leste-Oeste e nas decisões tomadas no âmbito da Organização do Tratado do Atlântico Norte. Isto porque, muito embora Charles De Gaulle não gozasse de muita popularidade em Washington ou nas colunas da imprensa americana naquela época, a verdade é que a política externa desenvolvida por Lyndon Johnson e por Dean Rusk, com sua preocupação de Bridge-Building estava mais próxima de Paris do que de Bonn. Com efeito, embora demonstrasse ressentimentos em relação à De Gaulle, o Departamento de Estado Americano, obcecado com os problemas da China e da Ásia e procurando alguns acordos básicos com a então União Soviética, pareceu não repelir inteiramente a ideia de uma única Europa que se estendesse do Atlântico aos Urais. Essa filosofia política se prendeu, até certo ponto, ao tratado de não proliferação nuclear, que muito beneficiaria a França, fosse ou não fosse ela signatária do mesmo ato internacional. A invasão da Tchecoslováquia, as ameaças brandidas à base dos Artigos 53 e 107 da Carta das Nações Unidas e a Reunião da Doutrina Brezhnev, vieram alterar substancialmente essa situação e colocou novamente a Alemanha numa posição chave dentro de todo o quadro do Ocidente.

Certamente, as decisões da Organização do Tratado do Atlântico Norte, poderiam, por exemplo, refletir essa situação nova, hoje sabida, que a necessidade que existiu num apoio soviético para conduzir Hanói, a uma posição menos intransigente em Paris, também levou os americanos, contra desejos da chancelaria alemã, a assumir uma atitude menos abertamente condenatória à invasão da Tchecoslováquia. Johnson e Rusk ainda fizeram o humanamente possível para evitar a derrocada da Détente, e por isso mesmo, russos e americanos, continuavam de mãos dadas em tudo que se referia à entrada em vigor e à implementação do tratado de não proliferação. A crise do ouro trafegou nestes mesmos juízos que permitiram encarara-la. Aos outros regimes monetários do ponto de vista dos mecanismos de funcionamento e da abrangência temporal, deixou-se de existir somente quando, um determinado número de países deixou não aceitou os seus três princípios ou regras tais como a monetização, a moeda doméstica, e o preço oficial fixo. O seu caráter expansionista foi suficiente para situar o déficit europeu, colocando-se, naturalmente, como 
problema de financiamento. A este respeito, as autoridades financeiras das instituições internacionais sempre foram otimistas dando mais financiamento a cobertura da zona dos déficits, desviando-se de meios inflacionários capazes de enfraquecer as principais moedas. A fórmula Rueff-Pinay, aplicada com todo o sucesso nos anos de 1950 mantinha desconhecida à medida da poupança disponível e dependia-se da mesma e de fatores múltiplos e variáveis de financiamento total dos déficits, através de empréstimos ao Setor Público. A política monetária francesa girou em torno de uma decisão fundamental: a de que a desvalorização do franco resultaria de uma situação crítica do balanço de pagamentos, mas não de crises artificiais provocadas pela especulação e sim de uma crise do dólar ou da libra forçaria uma reforma do sistema monetário internacional capaz de propiciar uma revisão geral das paridades das moedas e que, portanto, os males da conjuntura monetária mundial poderiam provocar uma solução de conjunto que, por si mesma, eliminaria a necessidade de o Governo francês tomar uma decisão sobre a paridade de sua moeda.

\section{O Plano Rueff: a França e a Crise}

A recuperação do dólar após a Confederação de Washington, em março de 1968, e as medidas anunciadas pelo então Presidente dos Estados Unidos para atacar as causas $e$ não mais os sintomas da inflação, e a convicção mais ou menos generalizada de que a Administração Nixon não modificaria o valor oficial do ouro, liquidaram praticamente, as esperanças francesas de ver resolvidos os problemas do franco à custa de uma desvalorização do dólar. A convicção da França de que o arsenal de recursos disponíveis seria sempre suficiente, não só para o desencorajamento da massa de capitais especulativos, como também a uma investida da solidariedade monetária internacional que, embora politicamente relativa e dinâmica, atua sempre em favor do Banco de Ajustamentos Internacionais da Basiléia BIS, complementarmente a conviç̧ão de que a situação desfavorável do balanço de pagamentos tende sempre a se corrigir. E, aquele que primeiro levantou protesto contra a privilegiada posição exercida pelo dólar como política de equilíbrio parece ter sido o economista francês Jacques Rueff, membro da Academia de Letras de França. Com grande influência junto ao Governo de seu país foi o mentor da reforma monetária que levou a França à adoção do chamado Franco Novo. Trata-se de economista da escola liberal, mas um dos últimos defensores do padrão ouro. Rueff se 
manifestou com veemência contra as ideias da Teoria Geral de Keynes e é considerado eminence grise do Governo do General De Gaulle em questões monetárias e financeiras. Como partidário do padrão ouro, Rueff não concordou com a solução de eliminação do ouro do sistema monetário internacional (EICHENGREEN, 2002, p. 67), sobretudo na compensação sugerida na Clearing Union de Keynes. Em seus escritos, insurge-se, Jacques Rueff, contra o chamado The gold-exchange standard (FERNANDES, 1967).

O desenvolvimento da questão monetária internacional não pareceu ter sido favorável à aspiração francesa de divisas orçada em US\$ 2 bilhões em três meses (1/3 das reservas totais do país), e as perspectivas de que esta última havia crescido ao ritmo de 100 e 200 milhões de dólares mensais ainda naqueles anos de 1960. Entretanto, suscitaram inquietudes sobre as reservas monetárias que resistiram à sangria e as primeiras dúvidas sobre se a questão monetária não foi colocada num círculo vicioso, em que o franco enfraqueceu por força dos controles impostos e que estes tenderiam a ser reforçados porque a moeda havia enfraquecido. No que toca ao Balanço de Pagamentos, embora os resultados da balança comercial em julho tivessem sido favoráveis $(6,11$ bilhões de francos de importações contra 6,39 bilhões de exportações, segundo dados oficiosos no final da década), o conjunto das operações com o exterior havia sofrido os efeitos de evasão sazonal (férias fora da França). Nos meses próximos era de se esperar, ainda, um incremento das importações devido à aceleração da expansão econômica, e era duvidoso que o mesmo fosse acompanhado por um aumento das exportações, pois esta época coincidia, justamente, com o período de ajustamento que seria iniciado pela rentrée de setembro (CARVALHO, 2004).

Os sistemas da fraqueza do franco eram bastante evidentes: a moeda valia de $10 \%$ a $12 \%$ menos no exterior que na França e os títulos das sociedades estrangeiras valiam de $12 \%$ a $15 \%$ a mais na Bolsa de Paris. Por outro lado, em complementação ao controle de câmbio, o Banque de France não comprou francos no exterior, com o duplo objetivo de estimular os turistas estrangeiros a despender, na França, a moeda francesa, e evitar que os nacionais se dirigissem ao exterior para comprar divisas estrangeiras, burlando, assim o teto de compra de moeda estrangeira estabelecido pelo controle cambial. Diante desses fatos, enquanto não eram corrigidas as causas estruturais da pressão sobre a moeda persistiria, o clima difícil tal como o período de paralisação da economia pelas greves daquele período 
emendou-se, praticamente, ao período de férias, e, dessa maneira, não havia sido processada até aquela data, a rentrée que marcaria o início efetivo da realidade econômica de pós-crise. Disto resultou, concretamente, que a economia francesa ainda não havia se expressado em função da nova escala salarial, vale dizer, não teve oportunidade de demonstrar a sua capacidade de absorver a explosão dos salários e, portanto, de provar a sua competitividade (SOLOMON, 1979).

O Governo Couve de Murville pediu dezoito meses para recolocar sobre os trilhos a economia e o curto lapso de tempo decorrido desde a crise não autorizou qualquer juízo de maior profundidade sobre as possibilidades de sucesso, pois as crises econômicas alemãs (como a de 1967) repercutiram intensamente sobre a França, e muito embora o Governo francês continuasse formalmente infenso à ideia da desvalorização do franco como tratou o General De Gaulle: a corrente político-econômica de opinião contrária encontrava-se, no momento, fortalecida, aliás, essa corrente vinha lançando sobre o Governo a responsabilidade da crise do franco, rejeitando a tese de que sua causa exclusiva eram os acontecimentos de maio-junho, tese que o Governo francês vinha explorando intensamente tanto no plano interno quanto no externo (KILSZTAJN, 1989).

Diversas causas, não diretamente imputáveis às greves, foram apontadas, ressaltando-se, dentre elas, o grande déficit das empresas nacionalizadas, de toda a maneira. O Governo De Gaulle começou a ressentir-se da autolimitação a que se impôs, colocando, logo após a crise de maio, a questão monetária como questão de honra do Governo, dando-Ihe, pois, uma dimensão política muito grande. Muito embora qualquer previsão objetiva sobre o futuro do franco pareça hoje prematura, a paralisação das operações da bolsa de Paris, decidida pelo Ministro Ortoli, constituiu expressão inequívoca das dificuldades com que ora se defrontava o Governo do Presidente De Gaulle no plano monetário. Propunha ao parlamento medidas fiscais tendentes a diminuir o excedente da balança comercial, através de um imposto sobre as exportações e uma bonificação para as importações. Juntando-se a todos esses fatos, foram anunciadas, a não abertura da bolsa de Paris e a realização em Bonn de uma Conferência do Grupo dos Dez para examinar a situação monetária internacional diante do panorama que se apresentava em razão de todos os fatos. A crise monetária não atingiu a França somente em termos da estabilidade de sua 
moeda, mas também da sua posição de princípio quanto ao sistema monetário internacional vigente (LELART, 1997).

O Ministro Couve de Murville regozijava-se de que a Conferência da Basiléia tinha confirmado a existência de uma solidariedade monetária internacional, referência implícita ao fato de que esta era capaz de propiciar uma solução para a crise, porém, alguns dos principais mentores das políticas monetárias francesa não ocultavam sua opinião de que a França não deveria colocar suas reservas monetárias a serviço de um sistema monetário internacional que julgavam iníquo, vale dizer, em defesa de moedas naquela época doentes. Se, por um lado, a valorização do marco alemão constituía numa solução de curto prazo para a crise, beneficiando, portanto, a França, por outro lado, as repercussões negativas que poderiam advir para a economia alemã não podiam deixar de suscitar graves preocupações para o Governo de Paris, pois propunha melhoria do balanço de pagamentos dos Estados Unidos, e dos movimentos especulativos acima mencionados, o risco de envolvimento do dólar não podia ser afastado se a efervescência do mercado mundial de câmbio viesse a se agravar (MEDEIROS, 1999).

Imediatamente após a Conferência da Basiléia, o Primeiro Ministro Couve Murville concedeu entrevista televisionada, com vista a dar ao país a versão oficial sobre a atual situação econômico-financeira e monetária, cujos pontos principais foram os seguintes: a) 0 franco foi enfraquecido e os franceses especulavam contra a sua moeda; b) As medidas restritivas do crédito eram provisórias e, caso a especulação cessasse seria possível que o Governo renunciasse às suas próprias decisões; c) O Governo empreendeu uma reforma do crédito de maneira a torná-lo mais livre e abundante, pois em matéria econômica tudo estava ligado ao crédito (tratava-se, evidentemente de manobra política dilatória, pois as medidas de 12 de novembro iriam justamente a sentido contrário); d) O Governo combateu a burocracia administrativa que prejudicava as empresas; e) Reduziu de 2 bilhões de francos o déficit no período (OESP, 20/02/1968).

\section{Os últimos dias do padrão ouro}

No plano internacional, as perdas de ouro e divisas, se acentuaram, devido à especulação sobre o marco alemão que girou em torno das possibilidades de sua revalorização, fato que, evidentemente, resultou em compras maciças daquela moeda, em 
detrimento particular do franco e da libra. Os Bancos da França e da Inglaterra tiveram de intervir para sustentar a cotação de suas moedas respectivas com relação ao marco. Paralelamente, as libras e os francos adquiridos pelo Banco Central da Alemanha, tendo sido transformados em dólares, provocaram uma valorização substancial dos haveres estrangeiros em dólares e dos títulos do tesouro norte-americano. Estas últimas operações se constituíram, aliás, numa pressão adicional sobre a cotação do franco e da libra. A situação da libra, por sua vez, foi enfraquecida em razão da especulação sobre o marco e sobre o franco. Apesar da desvalorização das balanças sterling o continuado déficit da balança comercial inglesa mantinha a libra em situação de vulnerabilidade face às crises monetárias (BELLUZZO, 1999, p. 56).

A situação do dólar arrestou o déficit orçamentário entre 1968 e 1969 demasiadamente elevados que atingiria um nível de forte inquietação nos meios financeiros, fazendo-os temer pela impossibilidade, de fato, de seu financiamento ser realizado inteiramente sem recurso a meios inflacionários que, necessariamente, debilitariam a moeda (GALL, 2009, p. 89). O movimento de fuga de capitais para o exterior resultante, dentre outras razões interdependentes, foi da majoração dos direitos de sucessão, e, igualmente, da supressão do controle cambial. O crescimento excessivo da liquidez, que levou o Ministro Finanças a tomar medidas provisórias de restrição do crédito, cujos efeitos sobre os movimentos do Hot Money não puderam não puderam sentir naquele momento, caracterizaram-se em medidas restritivas, anunciadas, juntamente com a elevação da taxa de desconto (de 5 para 6 \%) foram as seguintes: elevação dos depósitos compulsórios dos Bancos (de 4 para 4,5 \% para os depósitos à vista, de 2 a 2,5 \% para as outras exigibilidades), elevação de 13 para $14 \%$ do coeficiente de retenção (parte dos recursos líquidos que os Bancos não podiam considerar como disponibilidade para operações) (BORTOLANI, 1981).

A limitação do aumento das operações daquele curso redesenhou o panorama monetário internacional, marcando-o por uma viva e persistente agitação sobre os principais mercados mundiais de câmbio, assim como pela natural repercussão da mesma sobre os mercados do ouro. A presente efervescência tinha sido alimentada por fortes movimentos especulativos de capitais, que pressionaram, no sentido da baixa, o franco francês, e, no da alta, o marco alemão. Foi nesse contexto de tensões e apreensão que se iniciou em Basiléia, a Conferência dos Governadores dos Bancos Centrais da França, Alemanha, Grã-Bretanha, 
Bélgica, Holanda, Itália, Suíça, Suécia, Estados Unidos e Japão, que foi seguida por uma sessão de trabalho dos Governadores dos Bancos Centrais dos seis países do Mercado Comum (IMF, 2001).

Os resultados e as conclusões específicas dessa conferência só foram conhecidos nos termos da declaração do Primeiro Ministro Couve Murville, não obstante, podiam-se identificar no temário da Conferência de Basiléia alguns pontos principais nas causas mesmas da crise (GONTIJO, 2008, p. 34). Pois, a dificuldade financeira da França, apesar dos sintomas favoráveis no contexto de expansão econômica, se achava diante de uma etapa ameaçada, na Conferência de Basiléia, a promover uma desvalorização de sua moeda, suficientemente importante para desencadear um reajustamento geral. A que prenunciava a desvalorização do franco, como medida de compensação para uma revalorização apenas razoável do marco. Esta tese, sobre a qual se especulou intensamente, decorreu de interpretações de certas posições em Bonn e em outros centros financeiros. As medidas anunciadas pela Alemanha não solucionariam, por si sós, a crise, e que as mesmas deveriam ser complementadas por outras, tomadas por outros países. A nota do Wall Street Journal refletindo os meios bancários de Nova York naquele momento mostrava o fechamento da maioria dos mercados financeiros europeus, e uma espécie de presságio do realinhamento das taxas de câmbio entre o marco e o franco. A presença em Bonn de elementos do Comitê Monetário da CEE, que era o órgão de consulta em caso de alteração das paridades monetárias da França, que tornava excepcionalmente difícil, para este país, conformar-se com uma solução provisória que se constituísse num mero adiamento da crise; e finalmente os rumores vindos de Bonn no sentido de que o princípio de uma operação de desvalorização da moeda francesa foi admitido na reunião dos ministros das finanças dos Dez formaram o resultado de incerteza monetária internacional, tendo o dólar e o marco alemão beneficiando a si mesmos, no mercado de câmbio de Paris, com um prêmio de 3 a a 4 \% para o dólar, e 5 a $12 \%$ para o marco, relativamente às suas paridades oficiais com o franco (OESP, 12/06/1968).

Continuavam produzindo grande eco, as discussões dos Dez na Alemanha, em que um front franco-anglo-americano, ao quais os círculos monetários já se haviam desacostumado, parece ter sido constituído para pressionar a Alemanha a arcar com os maiores ônus da solução da presente crise. Ao que parece, a recusa do Governo alemão em 
revalorizar o marco e sua proposta alternativa de adotar medidas para reduzir o superávit da balança comercial do país, encontraram apoio da Suíça, Itália e Países Baixos, mas foram julgadas muito tímidas pelos Estados Unidos, França e Inglaterra e, sobretudo pelas duas últimas, cujas moedas vinham sofrendo envolvimento progressivo à medida que a crise se prolongava. Após as primeiras discussões em Bonn, consolidaram-se três correntes de opinião distintas: 1) a que continuava a recusar a hipótese de desvalorização do franco e revalorização do marco, vendo em medidas práticas tendentes ao reequilíbrio a solução não traumática da crise. Essas medidas eram suplementares às já anunciadas pelo Governo alemão, e outras, seriam tomadas pelo Governo francês, e talvez o inglês, no sentido da concessão de bonificação às suas exportações para a Alemanha; 2) a que previa um reajustamento geral das paridades das principais moedas, dólar libra franco e marco alemão, baseada, sobretudo, nos rumores de que a França havia ameaçado (OESP, 16/07/1968).

O fim do padrão ouro estabeleceu no dólar a paridade das moedas, e encaminhou para o sistema financeiro internacional a resolução dos principais problemas referentes aos créditos. A flutuação cambial na Europa nasceu do fim da paridade ouro, e mesmo ourodivisa e viabilizou a expansão comercial, financeira e monetária no sistema de flutuação, que marcou antecedentemente, a política comunitária de união econômica e monetária da Europa. Tal medida foi responsável por um grande afluxo de dólares em relação a moedas como o marco, com notória expansão de inflação entre os países da comunidade que viabilizou um crescimento econômico de caráter mais independente. Esta vantagem trouxe melhores posições competitivas à indústria alemã por exemplo. A viabilidade do próprio sistema financeiro internacional em ampliar liquidez internacional, estimulou o crescimento econômico mundial dos inicio dos anos 1970, e foi suficientemente capaz de formar nos países em desenvolvimento a atividade econômica aquecida que beneficiou o consumo e as demandas, como visto no Brasil nesse mesmo período. Porém é preciso que de trate que de um modo geral e sabidamente: a base de esquemas estabilizados de mercado, de natureza alegadamente consessional, é um ponto de vista e de convergência dos países desenvolvidos (SIMÕES DA SILVA, 2009, p. 87) que, passaram a operacionalizar as vendas e o comércio através do sistema financeiro em mecanismos de extração de investimentos. Em exemplo, temos durante o período que se estende por toda a segunda metade da década de 1970, a 
compra de petrodólares como saída à supervalorização desse óleo combustível, estruturado por Henry Kissinger durante o governo de Richard Nixon.

\section{A estabilidade monetária dos países desenvolvidos em conflito: a tensão Leste- Oeste}

O duopólio mundial de poder que dominou as relações internacionais desde o término da Segunda Guerra Mundial, pondo a Guerra Fria, como estrutura política capaz de envolver todos os continentes, fez pairar sobre eles a ameaça da catástrofe nuclear, e representou um tournant de evidente importância política e de enorme significação histórica. De acordo com o Professor Hélio Jaguaribe, a tendência histórica de longo prazo é de uma ordem mundial provisória, instantânea, capaz de organizar um sistema de coordenação em que cada vez mais se possa reconduzir a mesa de negociações o papel do centro decisório internacional que, por sua vez, passou a sofrer muito com as intervenções de uma comunicação global célere e imediata. A multilateralização financeira passou a desempenhar na dinâmica dos fluxos de capitais o papel de precípuo e permanente construtor de créditos para os países membros. E a cooperação internacional tornou-se proa das relações internacionais e ganhou ao longo do século XX o caráter de centralizador dos negócios financeiros e centro decisório para as operações financeiras entre os países. A busca permanente por reformas centrou-se no sistema financeiro internacional que pôs fim ao ouro, como moeda, e mesmo como alternativa financeira e creditícia.

Nesta esteira, os planos do então Primeiro Ministro Couve de Murville de consolidar o programa fiscal e financeiro do Governo da França para assegurar o crescimento da economia e defender a moeda. A exposição de motivos da referida lei indicou as grandes linhas do programa proposto pelo Governo: para evitar os riscos devidos a um excesso de liquidez foi decidido conter a expansão do crédito dentro dos limites estritamente necessários. Propôs-se uma redução maciça do déficit orçamentário através da compressão de despesas e de novas receitas. Com vistas a assegurar o equilíbrio do balanço de pagamentos e a continuação de uma indispensável expansão, previram-se medidas fiscais que permitiriam uma melhor proteção do mercado e a promoção das exportações. A redução do déficit era particularmente importante, posto que o mesmo passou de 11,7 bilhões de francos, previstos inicialmente, para 6,354 bilhões, ou seja, uma redução de 5,346 
bilhões. A compressão de despesas permitiu economias num montante de 2,841 bilhões, assim obtidas: redução das subvenções às empresas nacionalizadas, das despesas de funcionamento, de certas despesas de equipamento civil, do orçamento de equipamento das Forças Armadas, e das rubricas Empréstimos e adiantamentos e Intervenções econômicas (IMF, 2011).

Os aumentos de receita se elevaram a 2.505 milhões de francos, que foram obtidos através de uma elevação das taxas da Taxa sobre o Valor Agregado, TVA, variável. Outrossim, a elevação da TVA se destinou à proteção do mercado e a compensar a supressão do imposto sobre os salários (restrita esta última às empresas exportadoras). No momento, pareceu oportuno, no entanto, a elevação das taxas da TVA, correlata à supressão do imposto sobre salários, deveria promover o aumento das exportações e dos investimentos. Paralelamente, a expansão do consumo interno e das importações seria freada em razão das restrições sobre o crédito e das incidências da alta da TVA sobre os preços a varejo (CORRÊA, 1995, p. 45).

O aumento dos preços devia ser de 6\%, em 1969, e envolvia um risco de criar uma espiral inflacionária se houvesse uma continuação das reivindicações salariais. As repercussões do programa do Governo sobre a evolução da economia francesa estavam, naturalmente, ligadas aos problemas do franco e autorizavam as reflexões abaixo, sobre a decisão do Presidente De Gaulle de não desvalorizar a moeda. Uma frase do discurso do General De Gaulle, em 24 de novembro, pareceu ter sido essencial para uma interpretação de suas intenções, e, deixadas de lado as considerações políticas inerentes, não carecia de lógica financeira. Naquela situação, a operação de desvalorização correu forte risco de ser, um remédio, um artifício momentâneo de uma ruinosa facilidade e o prêmio pago aqueles que apostaram na queda do franco, momentos antes da queda do padrão ouro (LICHTENSZTEJN, 1987, p. 41).

De acordo com o Comitê dos Salários, dos quais participaram Jacques Rueff e Louis Armand e do então Ministro das Finanças Antoine Pinay, a decisão havia sido tomada a frio, quando concluído todo um processo de saneamento das finanças internas e externas da França, iniciado ainda nos anos 1950. Assim sendo, o franco foi desvalorizado após o início do programa de restabelecimento do equilíbrio financeiro, a fim de dar um impulso indispensável para que a balança comercial se transformasse em excedentária e que as 
reservas de ouro e de divisas se reconstituíssem. Esses dados permitiram interpretar a frase do General De Gaulle e o programa referido acima dentro da seguinte perspectiva: a) a desvalorização do franco não estava totalmente excluída para o futuro, mas ela estava para aquele momento; b) era forçoso reconhecer que uma desvalorização na situação atual teria tido resultados limitados, e, posto que já esperada psicologicamente por numerosos meios, ela correria o risco de transformar-se, efetivamente, num expediente fácil meramente corretivo de uma crise monetária. E era preciso considerar, por outra parte, a interpretação que o país daria à desvalorização. Fora dos meios econômicos e financeiros, ela sempre era interpretada como uma diminuição do poder de compra interno. Assim, após haver declarado que a desvalorização seria o pior absurdo, e, conhecendo a interpretação que teria tal medida, por parte da grande massa de assalariados, o General De Gaulle, se a houvesse aceito, estaria numa situação política perigosa. Em razão desses elementos psicológicos, parecia compreensível o fato de que o General tivesse escolhido a forma de um violento impacto para anunciar sua decisão, preparando, inclusive, o caminho para o programa governamental de disciplina econômica, financeira e monetária. A desvalorização do franco poderia ocorrer no futuro, mas a frio, quando houvesse um saneamento das finanças públicas (OESP, 12/08/1971).

Ainda de acordo com a nota publicada pela imprensa, as medidas de emergência adotadas dificilmente poderiam estabilizar a situação, mesmo por um curto prazo, pois a substância do problema não havia sido alterada. Também não existiam nos mercados capitalistas sujeitos às leis do lucro, forças que pudessem manter o preço duplo artificial imposto para a venda do ouro - o antigo, baixo, para pagamentos intergovernamentais e o novo, alto, para transações particulares; 3 ) a crise também revelava o estudo mórbido da economia dos principais países capitalistas, sendo o fator decisivo determinante da crise monetária a Guerra do Vietnã que acarretou déficit orçamentário e a inflação provocada pelas despesas militares descomedidas, mesmo para a economia americana (CHESNAIS, 1996, p. 56).

As decisões de Washington foram portadoras de indisfarçável desafogo, os meios franceses as interpretaram como um paliativo para a crise, por não terem atingido as causas a que a França, tradicionalmente, atribui os males do atual sistema monetário internacional. A despeito da crítica principal de que as decisões tomadas tinham apenas efeitos 
transitórios, é inegável que o clima naquele momento diferia bastante do que havia reinado, havia voltado à quase normalidade as operações de câmbio e voltavam também o dólar e a libra a serem aceitos sem as limitações quantitativas no início dos anos de 1970 que passaram, então, a vigorar. Podia-se dizer que a criação de dois cursos para o ouro foi à solução aqui considerada como a mais provável, por tratar-se da única aceitável pelos norteamericanos. Todavia, além da crítica ao mérito do sistema criado, antecipavam os meios franceses sérias dificuldades de caráter operativo, sobretudo no que se referia a não obrigação de vender ouro ao curso oficial para a substituição de quantidades vendidas por autoridades monetárias no mercado livre. O acordo de Washington representava a quase totalidade dos pontos de vista do Governo norte-americano, sendo que o programa traçado era indispensável em um elenco de medidas efetivas e rígidas para restabelecer o equilíbrio do balanço de pagamentos dos Estados Unidos. Por outro lado, de maneira geral, a imprensa francesa acentuava que mais uma vez a solução de um problema internacional da maior gravidade foi atingida sem que a Europa dela tenha participado em medida proporcional às suas possibilidades e responsabilidades (SAUL, 1991, p. 67).

\section{As principais críticas sobre o padrão ouro}

Certamente, as criticas sobre o padrão ouro fundamentam-se geralmente na disparidade causada não apenas no conflito monetário internacional, mas na própria instabilidade gerada nos mercados de produtos de base. O diagnóstico geral desse problema foi resultado das políticas protecionistas dos países desenvolvidos. As distorções provocadas por regimes de comercialização inadequados em vários países produtores, os efeitos nocivos da ação especulativa em bolsas, os ajustes do trade privado para divisão de mercados e depressão dos preços, são, entre outros, aspectos fundamentais do problema deficiências, que, de um modo geral, sabidamente carecerem de uma maior flexibilidade necessária à implementação de esquemas estabilizados de mercado, de natureza alegadamente concessional, do ponto de vista dos países desenvolvidos, pelo menos (MINSKY, 1986, p. 34).

Em consequência disso, as diretrizes da participação do Fundo e do Banco Mundial em programas de estabilização de preços, praticamente se cingiu a uma única inovação, e assim mesmo de caráter doutrinário, a saber, o reconhecimento do princípio de que o Fundo 
pôde e devia conceder financiamento para o estabelecimento de estoques reguladores. A este respeito, por exemplo, é relevante a alegada limitação estatutária segundo a qual o Fundo não pôde conceder empréstimos às organizações administradoras de acordos de produtos de base, mas sim apenas diretamente aos Membros do Fundo, no contexto de suas relações normais, com o que pôde também estabelecer um vínculo de condicionalidade entre a aprovação do FMI das políticas internas de produtos de base dos Membros e a concessão a estes dos empréstimos em causa. Em outras palavras, as premissas adotadas não permitiam que se atingissem as causas estruturais da instabilidade de preços de produtos primários, limitando-os a medidas paliativas de reequilíbrio em curto prazo das flutuações de receitas derivadas dessa instabilidade. Em verdade o Fundo deveria ter procurado, como instituição, influenciar a formulação das políticas de produtos de base dos países desenvolvidos, inclusive através de recomendações o mais possível coercitivas, que indicassem as medidas internas e externas conducentes às soluções diagnosticadas para aquele problema. O financiamento compensatório e as medidas para o aperfeiçoamento no âmbito da UCTAD, ou seja, da automaticidade da ampliação do limite de 25 para 50 por cento do direito de saque, necessidade de refinanciamento das dívidas em caso de queda persistente das receitas de exportação e maior importância nos cálculos da queda às receitas verificadas nos três anos precedentes: necessitariam do estabelecimento de um limite de 50 por cento da quota de cada país para o direito combinado de saque para fins do financiamento compensatório e de estoques e pôde dificultar a aprovação de pedidos de empréstimos de países que sofreram sucessivas quebras de receita. A liquidez do Fundo cumpre notar, não teve origem nos países subdesenvolvidos e, ainda, a experiência do funcionamento do esquema de financiamento compensatório desde o colapso do padrão ouro não indicou tendência ao argumento de pressão sobre a liquidez do Fundo e não foi aceito para a imposição de quotas estreitas, inclusive em vista dos fins de ajuda ao desenvolvimento, do novo tipo de financiamento a estoques a ser englobado pelo atual esquema de financiamento compensatório (MOLLO, 1988, p. 56).

O Banco Mundial, o Fundo Monetário Internacional e o Banco Interamericano de Desenvolvimento participaram diretamente na construção de dispositivos para o acesso a mercados através da implementação de condições ao comércio de produtos, oriundos pelos países desenvolvidos através da instabilidade dos mercados de produtos de base, resultado 
das políticas protecionistas dos países desenvolvidos, aceitando distorções provocadas por regimes de comercialização inadequados em vários países produtores. Alguns efeitos nocivos oriundos de ações especulativas em bolsas, por exemplo, acentuaram a depressão de preços, e é um aspecto fundamental de esquemas de mercado, de natureza alegadamente concessional, do ponto de vista dos países desenvolvidos (PLIHON, 1999, p. 78).

Assim mesmo, o fato mesmo da realização da transição das políticas de crédito para pós-padrão ouro é positiva, na medida em que representou a primeira tentativa, de participação direta das mais importantes instituições financeiras internacionais nos esforços multilaterais de estabilização de preço, e mesmo na busca por soluções de crédito. Nessas condições, sempre é digna de estímulo à atenção do FMI-BIRD sobre o assunto, ainda que, disso resultem apenas foros adicionais para a ação reivindicatória dos países em desenvolvimento, e mesmo com relação aos problemas do mercado internacional tradicionalmente ataca em organismos internacionais em seu caráter técnico.

Tal caráter liga-se ao financiamento compensatório, as reivindicações para o aperfeiçoamento do esquema permanecem aquelas de acordo com a necessidade de refinanciamento das dívidas em caso de queda persistente das receitas de exportação e maior importância nos cálculos da queda às receitas verificadas nos três anos precedentes. Quanto ao proposto esquema de financiamento de estoques reguladores, o estabelecimento de um limite para cada país para o direito combinado de saque para fins dos financiamentos compensatórios e de estoques acaba dificultando a aprovação de pedidos de empréstimos de países que tenham sofrido sucessivas quebras de receita, sendo conveniente o financiamento de esquemas de estabilização de mercados tem, por definição, objetivos de promoção do desenvolvimento, atingíveis apenas além do curto prazo, na maioria dos casos; d) quanto aos efeitos sobre a liquidez do Fundo, cumpre acentuar que o argumento de pressão sobre a liquidez do Fundo não deve ser aceito para a imposição de quotas estreitas, inclusive em vista dos fins de ajuda ao desenvolvimento, do novo tipo de financiamento a estoques a ser englobado pelo atual esquema de financiamento compensatório. 


\section{Considerações Finais}

Certamente, o final do padrão ouro e o estabelecimento do dólar como mantenedor das paridades de câmbio, regulador do padrão monetário internacional adiantou aos Estados Unidos os saldos em dólares da França, e contribuiu para que o Governo francês adotasse a politica de converter tais saldos em ouro, algo que, se não desagradou à opinião técnica dos Estados Unidos, colocou a França na posição de se apresentar ao mundo, com certo orgulho, como a segunda nação possuidora do maior estoque daquele metal naquele momento. Todavia, além da politica de converção de dólares em ouro, o governo da França, anunciou ao mundo, que a solução para eliminar o irracionalismo e a injustiça decorrentes do privilégio do dólar com o deficit na balança de pagamentos dos Estados Unidos, estaria na volta, por todas as nações, ao padrão ouro clássico.

A repercussão, causada por esta proposta, anunciada publicamente pelo presidente De Gaulle, foi de tal ordem que, desde 1905, se desencadeou Estados Unidos e na Europa, enorme controvérsia, estimulada pelos economistas americanos perante o Congresso Americano desde então. O retorno ao padrão ouro ortodoxo, a despeito de tudo o que se possa imaginar, dizer, escrever, à medida dos imensos acontecimentos internacionais do sistema monetário constitui no fato que ainda hoje cada moeda não conta senão por sua relação direta ou indireta, real ou imposta, com o ouro. Cumpre reconhecer nessa afirmação um elemento de verdade, pois que, de acordo com as cláusulas do Fundo Monetário Internacional, as moedas de todos os países dele participantes são, direta ou indiretamente, definidas em termos de uma quantidade de ouro do dólar americano. Todavia, em seu anacrônico ditirambo ao ouro, não se pode pensar em impor a cada país a maneira como deve conduzir-se internamente. Mas a lei suprema, a lei de ouro, e bem o caso de dizer, que é necessário repor em honra nas relações econômicas internacionais, a obrigação de equilibrar, uma zona monetária a outra, por entradas e saídas efetivas do metal precioso, em saldo dos pagamentos resultantes de suas trocas. Com isso, The gold-exchange standard, operaria um sistema mais primitivo ou menos adequado. O Fundo Monetário Internacional, instituído para assegurar, quanto possível, a solidariedade das moedas, ofereceria a todos os Estados um terreno apropriado, desde que se tratasse não de perpetuar esse padrão, mas antes substituí-lo. A essência de que ao mundo foi dito solenemente em Paris, no ano da 84 
graça de 1905, na era dos voos cósmicos, pela palavra oficial do Presidente de um país que se orgulha de sua tradição de cultura e racionalidade: como explicar que isso possa ter ocorrido na pátria de Pierre de Boisguilbert, o economista nascido no século 17, precursor daquilo que é mais avançado em matéria de reformas monetárias necessárias para evitar as injustiças do sistema monetário internacional?

O paradoxo da Tese De Gaulle-Rueff foi de identificar no ouro um tipo de moeda que, segundo ele, não traria a marca de qualquer país em particular. É óbvio que ele teria em mente, a privilegiada posição desfrutada pelo dólar no sistema monetário internacional. Se, porém todos os países seguissem a doutrina pregada por De Gaulle, convertendo seus saldos de dólares em ouro americano, para introduzir depois o padrão metálico nos respectivos países, não haveria ouro no mundo que chegasse para isso, dado o crescimento da riqueza mundial e o consequente aumento da moeda bancária pelo crédito.

Em verdade, os Estados Unidos nutrem o maior estoque do crédito do mundo, e naquele momento não poderiam converter em ouro o valor de todos os seus saldos em dólares nos bancos americanos. Não era, portanto, ignorado por Jacques Rueff, a solução de aumentarem nos Estados Unidos o preço do ouro. Poderia assim beneficiar a França, se os americanos aceitassem a tese de Jacques Rueff que a defendeu no Conselho Econômico e Social da França, em 18 de maio de 1965. Jacques Rueff salientava ali que com o sistema do The Gold-Exchange Standard não seria possível resolver o desequilíbrio na balança de pagamentos dos Estados Unidos, tese correta dada a preferência do mundo pelo dólar, ao invés de mercadorias. Supondo encontrar a solução no retorno ao padrão ouro, dizia Rueff que o sistema de pagamentos consistiria em trocar saldos em dólares por ouro, seja dentro daquele gold-exchange standard, seja com o recuo ao padrão-ouro. É curioso, porém, que ao mesmo tempo em que Rueff em seu depoimento sustentou que os países europeus tinham direito absoluto de trocar seus dólares por ouro, e os exortava a exercer esse direito, por outro lado, admitia que os americanos não poderiam satisfazê-lo, pois, ainda havia dois outros tipos de soluções. O primeiro seria adotar um dos planos de reforma do Fundo Monetário Internacional como foi o caso do plano Triffin, que foi o mais popular e uma solução lógica, embora perigosa, por dar a uma autoridade internacional a faculdade de criar moeda, e a segunda solução que consistiu em observar que o preço do ouro fora fixado em 1934, pelo Presidente Roosevelt a 35 dólares por onça e que desde então todos os preços 
dobraram nos Estados Unidos. Parecia, portanto, a Rueff, que o razoável seria dobrar o preço do ouro, em lermos de dólares. Com isso os americanos teriam um valor dobrado em dólares de seu estoque de ouro e consequentemente poderiam converter em ouro os saldos em dólares de países estrangeiros, que não os tivessem trocado antes por aquele metal. É óbvio, porém, que isso implicaria vantagem especial para a França que poderia então reconverter seu ouro em dólares, obtendo, portanto, mais dólares que antes.

Tal proposta, ao lado das críticas que De Gaulle fez aos Estados Unidos foi repelida pela opinião técnica de seu staff. Ela implicaria não só em dar um presente à França e aos países produtores de ouro, como a Rússia e a África do Sul, mas também em fazer voltar a corrente de ouro para os Estados Unidos onde a opinião mais esclarecida, via com satisfação a redução do estoque de ouro do Fort Knox. De qualquer maneira foi esse tipo de pressão exercido pela França o que levou como vimos anteriormente, economistas como Emile Despres, Fritz Machlup, Leland Yeager e Robert Slevens a sugerirem que os Estados Unidos deveriam anunciar que estariam dispostos a converter todos os saldos em dólares em ouro até que este se esgotasse, mas declarando concomitantemente que não mais adquiririam ouro pelo mesmo preço ou por preço algum. Esbarrava assim a proposta de Rueff em reação inteiramente desfavorável aos objetivos da solução que apresentava. É interessante, porém, notar que Rueff não ignorava a resistência americana à ideia de aumentar o preço do ouro. No mesmo depoimento perante o Conselho Econômico e Social relatou ele que quando de uma visita aos Estados Unidos tivera a oportunidade de ouvir de um Diretor do Sistema de Reserva Federal daquele país, a afirmação de que três presidentes já haviam declarado que não mudariam o preço do ouro e que, portanto, estavam moralmente comprometidos a não fazê-lo. Certamente, está seria uma resposta de uma natureza, que envolvendo uma espécie de coação moral, não pôde contribuir para que os americanos mudassem sua política, satisfazendo seus desejos, ao menos daquela forma, como também os interesses da França.

Neste episódio, tem-se a impressão de que houve uma inversão da chamada ingenuidade dos americanos com relação à sagacidade gauleza. Não é de estranhar, pois, que o resultado dessas e de outras atitudes de autoridades francesas relativamente ao problema do deficit na balança de pagamentos dos Estados Unidos tenha se refletido na reação de economistas americanos abertamente favoráveis à desmonetização do ouro. Nesse sentido, como que advertindo a França, três desses economistas considerados 
influentes nos círculos oficiais de Washington, como Despres, Kindleberger e Walter Salant, publicaram em 5 de fevereiro de 1965, em Londres, na conhecida revista The Economist um artigo com o titulo The Dollar and World Liquidity em que de forma clara foi apresentado que se a Europa imprudentemente preferiria converter dólares em ouro, sendo que os Estados Unidos poderiam restaurar um verdadeiro sistema de moeda-reserva, mesmo sem a cooperação europeia. Isto porque o dólar se mantém em posição especial como moeda mundial. Esclarecia ainda que a América poderia realizar isso de várias maneiras inclusive pela diferença de preço entre a compra e a venda do ouro, ou privando o ouro de sua atual ilimitada conversibilidade em dólares. Os três reputados economistas Despres, KindLeberger e Salant sustentaram a tese que o déficit na balança de pagamentos é benéfico aos Estados Unidos e ao resto do mundo. Outro exemplo dessa reação, manifestado e em aberta simpatia pela total desmonetização do ouro, aparece nos escritos do Prof. Harry G. Johnson, da Universidade de Chicago. Johnson manifestava a opinião de que a desmonetização desse metal é resultado lógico de um processo que substituiria o ouro por um sistema monetário internacional inteiramente baseado no crédito. Segundo o autor há possibilidades de que o afastamento do ouro de seu papel monetário é possível diante do desencanto com a atitude de países que a América ajudou generosamente na reconstrução do pós-guerra. A acabar com a conversibilidade de dólares em ouro, ou de ouro por dólares, teríamos aí, portanto, mais algumas amostras da reação que causa nos Estados Unidos o déficit na balança de pagamentos.

Ainda nesse sentido, e como a maior economia da zona euro, a Alemanha pode desempenhar um papel central na resposta aos desafios colocados pela crise de créditos que vem se arrastando no sistema monetário desde então. Articulando formas mais claras, visão partilhada da União Econômica e Monetária de uma arquitetura pós-crise de reforma uma estrutural em vários países da área do euro poderiam incluir o uso de fundos estruturais da UE e aumentar a capacidade de empréstimo do Banco Europeu de Investimento pelo reequilíbrio natural da economia da Alemanha. Neste contexto, consistente com o mandato do Banco Central Europeu, as pressões desinflacionarias incipientes nas economias periféricas, essenciais para o seu realinhamento dos preços relativos, e poderia também na oportunidade para realizar as suas próprias reformas estruturais para elevar ainda mais o potencial de crescimento e diversificar suas fontes, reforçando ritmo das reformas na área 
do euro. Um maior crescimento no mercado interno impulsionado ajudaria a aumentar o potencial da economia acima do previsto no âmbito da linha de base ao gerar repercussões positivas do interior do euro para fora.

\section{Referências}

BELLUZZO, Luis Gonzaga. Finança Global e Ciclos de Expansão. In: FIORI, José Luís (Org.). Estados e Moedas no Desenvolvimento das Nações. Petrópolis, Rio de Janeiro: Vozes, 1999. (Coleção Zero à Esquerda).

BORTOLANI, Sergio. A Evolução do Sistema Monetário Internacional. Lisboa: Edições 70, 1981.

CARVALHO, Fernando Cardim de. Bretton Woods aos 60 anos. Novos Estudos CEBRAP, São Paulo, n. 70, p. 51-63, nov. 2004.

CHESNAIS, François. A Mundialização do Capital. Tradução de Silvana Finzi Foá. São Paulo: Xamã, 1996.

CORRÊA, V.P. A Estrutura de Financiamento Brasileira e a Oferta de Financiamento de Longo Prazo. Tese (Doutorado em Economia) - UNICAMP, Campinas, SP.

EICHENGREEN, Barry J. A Globalização do Capital: Uma História do Sistema Monetário Internacional. Trad. Sergio Blum. São Paulo: Editora 34, 2002.

GALL, Norman. O Terremoto Financeiro: a primeira crise global do século XXI. Rio de Janeiro: Elsevier, 2010 (impressa em 2009).

GONÇALVES, Reinaldo et al. A Nova Economia Internacional: uma perspectiva Brasileira. 8 a. Edição. Rio de Janeiro: Campus, 1998.

GONTIJO, Cláudio. Raízes da Crise Financeira dos Derivativos Subprime. Belo Horizonte: UFMG/Cedeplar, 2008.

KILSZTAJN, Samuel. O Acordo de Bretton Woods e a Evidência Histórica: o sistema financeiro internacional no Pós-Guerra. Revista de Economia Política, v. 9, n. 4, out./dez. 1989.

LELART, Michel. O Sistema Monetário Internacional. Portugal: Terramar, 1997. 
LICHTENSZTEJN, Samuel; BAER, Monica. Fundo Monetário Internacional e Banco Mundial: Estratégias e Politicas do Poder Financeiro. Tradução de Nathan Giraldi. São Paulo: Editora Brasiliense, 1987.

MEDEIROS, Carlos A.; SERRANO, Franklin. Padrões Monetários Internacionais e Crescimento. Petrópolis: Vozes, 1999.

MINSKY, Hyman. Stabilizing an Unstable Economy: New Havem. Yale University Press, 1986.

PLIHON, Dominique. Desequilíbrios Mundiais e Instabilidade Financeira: a responsabilidade das políticas liberais. Um Ponto de Vista Keynesiano. In: CHESNAIS, F. A mundialização financeira: gênese, custos e riscos. trad. C. Caccicarro et al. São Paulo: Xamã, 1999.

SAUL, Nestor. Euromercados. Porto Alegre: Ed. Ortiz, 1991.

SIMÕES DA SILVA, Luiz Afonso. Ensaios do IEEI, n. 2. Sistema Financeiro Internacional - Quo Vadis? São Paulo: UNESP, 2009.

SINGER, Paul. O Capitalismo: sua Evolução, sua Lógica e sua Dinâmica. São Paulo: Ed. Moderna, 1993.

SOLOMON, Robert. O Sistema Monetário Internacional 1945-1976. Rio de Janeiro: Zahar Editores, 1979.

STIGLITZ, Joseph E. A Globalização e seus Malefícios: a Promessa não-cumprida de Benefícios Globais. São Paulo: Futura, 2002.

TEIXEIRA, Aloisio. Estados Unidos: a 'Curta Marcha' para a Hegemonia'. Petrópolis: Vozes, 1999.

WILLIAMSON, John. A Economia Aberta e a Economia Mundial: um Texto de Economia Internacional. Tradução de José Ricardo Brandão Azevedo. Rio de Janeiro: Campus, 1989.

Artigo recebido em 18/07/2012 e aprovado para publicação em 17/08/2012. 
